\title{
The epidemiology of anotia and microtia
}

\author{
John Harris, Bengt Källén, Elisabeth Robert
}

\begin{abstract}
We studied a large data set from three registries of congenital malformations (central-east France, Sweden, and California), a total of 954 cases, known chromosome anomalies excluded. The prevalence at birth varied significantly between programmes, probably to a large extent because of different ascertainment and inclusion criteria, from 0.76 per 10000 births in the French programme to 2.35 in the Swedish. Within the California programme, there is a racial variability in prevalence with lower values among whites (and probably blacks) than in Hispanics and Asians. Also the proportion of anotia and microtia varies between races with the lowest proportion of anotia in whites. Anotia and microtia are equally often associated with other malformations and show other similar epidemiological characteristics. In unilateral cases, the right side is more frequently malformed than the left side, especially when the ear malformation is isolated. There is a male excess, most pronounced in isolated forms. Among associated malformations, facial clefts and cardiac defects are the most common ones (each about $30 \%$ of infants with associated malformations), followed by anophthalmia or microphthalmia $(14 \%)$, limb reduction defects or severe renal malformations $(11 \%)$, and holoprosencephaly (7\%). There is a maternal parity effect seen, an increased risk at parity 4+ (standardised for maternal age), more pronounced for anotia than microtia.

(F Med Genet 1996;33:809-813)
\end{abstract}

Key words: anotia; microtia; epidemiology; malformation registry.

California Birth

Defects Monitoring Program, Emeryville, CA, USA

$\mathrm{J}$ Harris

Tornblad Institute, University of Lund Biskopgatan 7, S-223 62 Lund, Sweden B Källén

Institut Européen des Génomutations, Lyon, France

E Robert

Correspondence to: Professor Källén. Received 12 February 1996 publication 28 May 1996
Hypoplastic and malformed ears, microtia, are common components in malformation syndromes, including those caused by chromosome anomalies. Such defects are also typical components of thalidomide ${ }^{1}$ and isotretinoin ${ }^{2}$ embryopathies. They may therefore be of special interest in studies of other possible teratogenic factors, including drugs. In its most severe form, microtia is represented by complete or nearly complete absence of external ears, anotia.

Relatively little has been published on the descriptive epidemiology of this malformation. Recently, data were reviewed on 172 infants with microtia or anotia, reported to the Italian Multicentre Birth Defects Registry during the years 1983-1992. ${ }^{3}$ These findings prompted us to report the results of our data on this malformation, collected from three large registers of congenital malformations.

\section{Material and methods}

The three registries used will be briefly summarised.

In central-east France (previously called France: Rhone-Alps/Auvergne Registry) a regional, population based malformation monitoring registry is at present based on approximately 100000 annual births. ${ }^{4}$ Stillbirths are registered at a gestational age of 28 weeks or more. Malformations are ascertained up to the age of one year by voluntary reporting from the hospitals in the region combined with a search of delivery records in the main delivery hospitals in the area. Data for 1978-1992 were used, which included a total of 1319757 births.

In Sweden, a national, population based system of congenital malformation registration is at present based on approximately 120000 annual births. ${ }^{5}$ Stillbirths are registered at a gestational age of 28 weeks or more. Malformations are ascertained by compulsory reporting of malformations detected in the neonatal period and from copies of the medical records kept by the paediatricians who investigate all newborn infants in the country. Data for 19731991 were used, which included a total of 1950148 births.

In California, the California Birth Defects Monitoring Program is a regional, population based registry of congenital anomalies currently based on 300000 annual births. ${ }^{6}$ Stillbirths are registered from 20 weeks onwards. CBDMP staff visit all hospitals and outpatient genetic centres to abstract data about all children with congenital anomalies diagnosed up to the age of 1 year. For every specific diagnosed anomaly, CBDMP staff record (1) the type of physical examination/ medical procedure/confirmatory test, and (2) the specific subspecialist making the diagnosis. Data for 1983-1991 were used, a total of 1921698 births. In order to obtain comparable material, only stillbirths older than 28 completed weeks were included from the California register.

Anotia and microtia were reported to the registers as diagnoses but often together with detailed descriptions of the actual appearance of the ear, including drawings or photographs. Anotia was counted as absence or nearly complete absence of the external ear, and microtia as clearly reduced and abnormal external ears. In some cases in the French and Swedish files, a classification of a severe ear malformation into anotia or microtia could not be made: these were labelled "unspecified". 
Table 1 Number of infants with anotia or microtia and prevalence (per 10000 births) reported from each registry (chromosome anomalies excluded)

\begin{tabular}{|c|c|c|c|c|c|c|}
\hline \multirow[b]{2}{*}{ Malformation } & \multirow[b]{2}{*}{ Isolated/associated } & \multirow[b]{2}{*}{ France } & \multirow[b]{2}{*}{ Sweden } & \multicolumn{2}{|l|}{ California } & \multirow[b]{2}{*}{ Total } \\
\hline & & & & All & Whites & \\
\hline \multirow[t]{4}{*}{ Anotia } & Isolated & 35 & 25 & 11 & 0 & 71 \\
\hline & Associated & 14 & 15 & 22 & 2 & 51 \\
\hline & Total & 49 & 40 & 33 & 2 & 122 \\
\hline & Prevalence & 0.37 & 0.21 & 0.17 & 0.02 & 0.23 \\
\hline \multirow[t]{4}{*}{ Microtia } & Isolated & 28 & 274 & 183 & 44 & 485 \\
\hline & Associated & 20 & 132 & 169 & 62 & 321 \\
\hline & Total & 48 & 406 & 352 & 106 & 806 \\
\hline & Prevalence & 0.37 & 2.08 & 1.83 & 1.15 & 1.55 \\
\hline \multirow{4}{*}{ Unspecified } & Isolated & 12 & 9 & 0 & 0 & 21 \\
\hline & Associated & 1 & 4 & 0 & 0 & 5 \\
\hline & Total & 13 & 13 & 0 & 0 & 26 \\
\hline & Prevalence & 0.09 & 0.07 & 0.00 & 0.00 & 0.05 \\
\hline \multirow[t]{3}{*}{ Total } & & 110 & 459 & 385 & 108 & 954 \\
\hline & Prevalence & 0.83 & 2.35 & 2.00 & 1.17 & 1.84 \\
\hline & $95 \% \mathrm{CI}$ & $0.68-0.99$ & $2.14-2.58$ & $1.80-2.20$ & $0.96-1.42$ & $1.72-1.95$ \\
\hline
\end{tabular}

$95 \% \mathrm{CI}=95 \%$ confidence interval.

Associated malformations were counted as major malformations, not directly related to the ear malformation. Infants were divided into three groups: isolated anotia/microtia without any associated major malformation; associated anotia/microtia when other major malformations were present; and chromosomal cases when a known chromosome anomaly existed. The latter group consists of 52 infants (seven Down syndrome, 19 trisomy 18, 17 trisomy 13, and 14 with other, different chromosome anomalies). Infants with chromosome anomalies were excluded from the analysis.

The statistical relationship between associated malformations was studied using the methodology first proposed by Källén and Winberg. ${ }^{7}$ The purpose was to identify patterns of malformations which seem to form an entity, caused by an (unknown) common aetiology or pathogenetic pathway. If the infants under study are defined by the presence of malformation A (in this case anotia or microtia), and some have malformation B and some malformation $\mathrm{C}$, these three should occur together more often than would be caused by chance. This means that infants with $A+B$ should have $C$ more often than infants with $A$ without $B$ and infants with $A+C$ should have $B$ more often than infants with $A$ without $C$. In order to enter a non-random association, the malformation must occur at an increased rate in the association compared with multimalformed infants without this association. This analysis is primarily made with inclusion of infants with a stated syndrome diagnosis. The reason for this is fully discussed by Källén. ${ }^{8}$ A second analysis was made after exclusion of definite genetic or teratogenic syndromes.

Confidence limits of rates are based on normal approximations. Frequencies were com-

Table 2 Racial distribution of anotia and microtia within the California programme

\begin{tabular}{llllll}
\hline & \multicolumn{3}{l}{ No of cases } & & \\
Race & Anotia & Microtia & Total & per 10 000 & $95 \%$ CI \\
\hline Whites & 2 & 106 & 108 & 1.17 & $0.96-1.42$ \\
Hispanics & 19 & 179 & 198 & 3.23 & $2.79-3.71$ \\
Blacks & 4 & 14 & 18 & 1.22 & $0.72-1.93$ \\
Asians & 4 & 26 & 30 & 2.18 & $1.47-3.12$ \\
Other & 2 & 22 & 24 & 2.66 & $1.70-3.96$ \\
\hline
\end{tabular}

pared using chi-square tests. The effects of maternal age and parity were studied using the Mantel-Haenszel ${ }^{9}$ technique after suitable stratifications. The $95 \%$ confidence intervals of the odds ratios were determined with a test based method. ${ }^{10}$ Heterogeneity between strata was tested with the Breslow and Day technique. ${ }^{11}$ Tests for time trends were performed using the Cochran-Armitage technique. ${ }^{12}$

In studies on the effect of maternal age and parity, the total birth populations were used as a reference. This could only be done for the Swedish and Californian material as crossed age-parity data were not available for the French population.

\section{Results}

PREVALENCE AT BIRTH

We have records of 954 infants with anotia or microtia excluding 57 infants with known chromosome anomalies. This represents a prevalence of 1.84 per 10000 but it varied between programmes (table 1): 0.83 in France, 2.35 in Sweden, and 2.00 in California. The French prevalence increased markedly during the observation period. For the period 19871992, a prevalence of 1.15 per 10000 was found. The increasing rate is statistically highly significant: a test for linear trend gives a chi-square of 11.4 at $1 \mathrm{df}, \mathrm{p}<0.001$. The proportion of anotia and microtia was the same before and after 1987 in the French programme. In California and Sweden no increase in prevalence was seen during the observation period, and in Sweden there was even a decrease.

In California there is a significant racial variation, from 1.17 in whites to 3.23 in Hispanics (table 2). The prevalence among whites is closer to that in the French material than to that in the Swedish material. The odds ratio (with whites $=1.0$ and stratified for year of birth) is: Hispanics 2.91 (95\% CI 2.30-3.68), blacks 1.06 (0.64-1.74), Asians 1.87 (1.252.78 ), and other races 2.25 (1.46-3.45).

For both anotia and microtia, a significant variability in prevalence exists between programmes, but it is much more marked for microtia than for anotia (table 1). There is a factor of two between the French and the Californian prevalence of anotia (the French one 
Table 3 Malformations registered as associated with anotia or microtia arranged according to frequency and with number of infants with microtia shown separately. Percentages are expressed based on all infants with anotia or microtia ("All") or on infants with anotia or microtia combined with other major malformations ("Associated only")

\begin{tabular}{lllll}
\hline & Number & & \multicolumn{2}{c}{ \% of infants with anotia or microtia } \\
\cline { 2 - 3 } \cline { 4 - 5 } Malformation & All & Microtia & All & Associated only \\
\hline Facial cleft & 118 & 98 & 12.4 & 31.4 \\
Cardiac defect & 115 & 97 & 12.1 & 30.6 \\
An/microphthalmia & 53 & 43 & 5.6 & 14.1 \\
Limb reduction defect & 42 & 33 & 4.4 & 11.2 \\
Severe kidney anomaly other than cystic kidney & 30 & 25 & 3.1 & 8.0 \\
Holoprosencephaly & 27 & 23 & 2.8 & 7.2 \\
Oesophageal atresia & 26 & 21 & 2.7 & 6.9 \\
Anal atresia & 25 & 19 & 2.6 & 6.9 \\
Positional foot defect & 23 & 18 & 2.3 & 6.9 \\
Choanal atresia & 22 & 18 & 2.0 & 6.1 \\
Microcephaly & 19 & 18 & 1.6 & 4.0 \\
Hydrocephalus & 15 & 12 & 1.6 & 4.0 \\
Hypospadias & 15 & 12 & 1.5 & 3.7 \\
Syndactyly & 14 & 12 & 1.5 & 3.7 \\
Polydactyly & 14 & 14 & 1.3 & 3.2 \\
Spina bifida & 12 & 10 & 1.0 & 2.7 \\
Intestinal atresia & 10 & 6 & 0.8 & 2.7 \\
Cystic kidney & 10 & 8 & 0.8 & 2.1 \\
Diaphragmatic hernia & 8 & 6 & 0.7 & 2.1 \\
Craniostenosis & 8 & 8 & 0.5 & 1.9
\end{tabular}

being the higher, chi-square $=11.5, \mathrm{p}<0.001$ ) and a factor of more than five between the Californian and French prevalence (the Californian prevalence being the higher, chi-square $=136.6, \mathrm{p}<0.001)$. The Swedish and Californian prevalence of anotia is similar (chi-square $=0.56, \mathrm{p}=0.45$ ) and there is no significant difference in prevalence of microtia between the two programmes (chi-square $=3.1, p=0.08$ ).

The proportion of anotia cases also varies significantly between races in the California programme, from $2 \%$ among whites to $10 \%$ among Hispanics and $14 \%$ among other races (blacks, Asians, and others). An analysis of heterogeneity gives a chi-square $=12.1$ at $4 \mathrm{df}$, $\mathrm{p}=0.017$ ).

ASSOCIATED MALFORMATIONS

There is no statistically significant difference in the proportions of infants with associated malformations between anotia and microtia: the odds ratio is 1.31 with a $95 \%$ confidence interval of 0.84-2.05 (stratification for programme and year of birth). There is a higher proportion of associated cases in the California programme $(49.6 \%)$ than in the French $(31.8 \%)$ and Swedish (32.8\%) ones. The difference in proportions is statistically highly significant (chi-square $=27.6$ at $2 \mathrm{df}, \mathrm{p}<0.001$ ).

Among the 376 infants with associated malformations, 89 were labelled with "syndrome" names $(9.3 \%$ of all), the majority from California. There were 59 with Goldenhar, 14 with Treacher Collins, and four with Nager; the remaining 12 all had different "syndrome" names.

Table 3 shows the most common associated malformations present. About $30 \%$ of all infants with associated malformations had a facial cleft and about equally many had a cardiac defect. An- or microphthalmia was found in about $14 \%$, limb reduction defects in $11 \%$, a severe renal anomaly in about $11 \%$, and holoprosencephaly in $7 \%$. There was a marked variability between the programmes in the number of each specific associated malformation, notably for hydrocephalus and microcephaly (most common in California), holoprosencephaly (most common in Sweden), and cardiac defects (less common in France). For some other malformations, like facial clefts, the frequencies were similar between the programmes.

We searched the material for triplets of malformations (anotia/microtia and two more malformations). We found a significant association between the ear malformation, holoprosencephaly, and an- or microphthalmia $(p=0.009)$ and also between ear malformation, neural tube defect, and facial cleft $(p<0.05)$. Removal of cases with a known genetic or teratogenic syndrome did not change these associations. At least some of these infants may represent unidentified trisomy 13 or related syndromes and this constellation of malformations is also included in the holoprosencephalic sequence.

BILATERALITY AND SIDEDNESS

There was a higher proportion of bilateral ear malformations when they were associated with other malformations than when they were isolated: the odds ratio for bilaterality in associated cases $v$ isolated cases (stratifying for programme) was 4.75 (95\% CI 3.29-6.86).

There is a marked excess of right sided malformations among unilateral cases when the side was known: 375 right sided and 240 left sided. Thus, $61 \%$ were right sided $(95 \%$ confidence interval 57-65). Right sidedness was slightly more common in isolated forms than in associated forms (OR $=1.45,95 \% \mathrm{CI}$ 1.03-2.02).

SEX OF INFANT

The sex ratio is significantly increased in isolated forms $(1.66,95 \%$ CI $1.40-1.97)$. It is also increased in associated forms $(1.24,95 \%$ CI 1.01-1.53) but the confidence interval encompasses the normal sex ratio of 1.06 . The 
Table 4 Comparison between infants with anotia and microtia for some epidemiological characteristics, expressed as odds ratios (anotia $v$ microtia) after stratification for programme, year of birth, and, when relevant, isolated/associated

\begin{tabular}{lll}
\hline Characteristics & $O R$ & $95 \% C I$ \\
\hline Male & 0.90 & $0.56-1.45$ \\
Bilaterality & 0.84 & $0.46-1.52$ \\
Right sidedness & 1.17 & $0.68-2.00$ \\
Maternal age 35+ years & 1.92 & $0.96-3.85$ \\
Parity 4+ & 2.12 & $1.24-5.14$ \\
Associated malformations & 1.31 & $0.84-2.05$ \\
\hline
\end{tabular}

male excess is significantly higher in isolated than in associated forms (OR for males in isolated $v$ associated forms is $1.33,95 \%$ CI $1.02-$ 1.74). There is no difference in sex ratio between bilateral and unilateral cases: OR for males in bilateral $v$ unilateral forms after stratification for isolated/associated is $1.01(95 \% \mathrm{CI}$ $0.71-1.42$ )

\section{MATERNAL AGE AND PARITY}

We found a slightly increasing trend in the prevalence at birth of anotia-microtia with maternal age (based on data from Sweden and California). For isolated and associated cases together, the odds ratio, stratified for programme, race (in California), year of birth, and parity, increases from 0.87 in the age group $15-19$ years to 1.41 in the age group $40+$ and the excess risk at maternal age $35+$ reaches statistical significance $(1.47,95 \%$ CI 1.16-1.87). This may at least partly be the result of unidentified trisomies.

If the risk at parity 1 is 1.0 , the odds ratio at parity 2 (after stratification for programme, race, and maternal age) was 0.96 , for parity 3 it was 0.95 , and for parity $4+1.17(95 \% \mathrm{CI}$ 1.03-1.33). There is thus a parity effect only in the highest parity stratum.

COMPARISON OF ANOTIA AND MICROTIA

Some epidemiological characteristics have been compared between anotia and microtia. These comparisons were made after stratification for programme and race, year of birth, and, when relevant, isolated/associated. The results are shown in table 4 as odds ratios (anotia $v$ microtia) with $95 \% \mathrm{CI}$.

There are no statistically significant differences between anotia and microtia with respect to bilaterality, right sidedness, sex ratio, or presence of associated malformations. High maternal age (35+ years) and high parity (4+) were both risk factors for anotia or microtia; for both, the odds ratios for anotia $v$ microtia are raised and for parity it reaches statistical significance.

\section{Discussion}

We found an average prevalence at birth of infants with anotia or microtia of 1.84 per 10000 which is higher than that described from Italy, 1.46 per $10000,{ }^{3}$ but the latter is higher than that found among Californian whites ( 1.17 per 10000$)$. There was, however, a marked variability between programmes with a much lower prevalence in France than in the other two programmes and a high prevalence in Sweden. This may be an effect of ascertain- ment but probably to a large extent also because of inclusion definitions. An increase in the prevalence with time was seen in France which could be the result of increasing ascertainment or changed definitions, or could represent a true increase, not seen in the other two programmes.

Microtia is difficult to define and the term may clinically be used with considerable variability. It is therefore understandable that the reporting and recording of the malformation may vary. Anotia (or type IV microtia) is more clearly defined, but it can be noted that the term is probably more frequently used in the French data set than in the Californian. In spite of the fact that the total prevalence of anotia or microtia cases was lower in France than in California, the anotia prevalence was nearly twice as large in the former programme than in the latter with the Swedish prevalence intermediate. Another possibility is a truly high prevalence of anotia in France, for example, owing to the presence of a specific teratogen.

Much of the programme variability shown in the data published by the International Clearinghouse for Birth Defects Monitoring Systems, ${ }^{13}$ from a low 0.1 per 10000 (Czechoslovakia) to a high 6.4 per 10000 (Mexico) may be the result of different inclusion criteria and different ascertainment.

Our further analysis showed no clear cut differences in the majority of epidemiological characteristics between anotia and microtia. The only exceptions were the effect of high parity and (possibly) high maternal age which were more marked for anotia than microtia. It may therefore be of little use to differentiate them from an epidemiological point of view. The problem of inclusion criteria still remains. Even though clear cut definitions can be set up and different types can be defined, they may be of little practical use in the handling of large data sets for monitoring or other epidemiological purposes.

The variable recording of infants with anotia/microtia may also be of importance within a programme if different hospitals or regions apply different diagnostic criteria. It can result in a false uneven geographical distribution. It is, however, also possible that true geographical variations exist. An example is anotia or microtia in South America ${ }^{14}$ with a very high prevalence in Quito, Ecuador.

We also showed a significant difference in prevalence between races in the Californian programme where definitions and ascertainment are probably the same, irrespective of race. We found a comparatively low prevalence in whites and blacks and a significantly higher prevalence in Hispanics, Asians, and "other" races. This definitely argues for a genetic component in the aetiology of the malformations. It can also be noted that the most severe forms (anotia) made up a larger proportion in Hispanics than in whites.

Most of our other observations on the epidemiological features of this group of malformations agree with those recently published from Italy. $^{3}$ One exception is the effect of parity. From the Italian data an increased risk was 
found for parity 1 while we, if anything, found the opposite, an increased risk for high parity women $(4+)$. The material on which we based our observation (Sweden and California) is nearly five times larger than the material published by Mastroiacovo et al. ${ }^{3}$ Even though population differences may exist, it seems more likely that the finding in the Italian material of an excess risk for first parity was a random finding.

1 Smithells RW, Newman CGH. Recognition of thalidomide defects. F Med Genet 1992;29:716-23.

2 Lynberg MC, Khoury MJ, Lammer EJ, Waller KO, Cordero JF, Erickson JD. Sensitivity, specificity, and positive predictive value of multiple malformations in isotretinoin embryopathy surveillance. Teratology 1990;42:513-19.

3 Mastroiacovo P, Corchia C, Botto L, Lanni R, Zampino G, Fusco D. Epidemiology and genetics of microtia-anotia: a registry based study on over one million births. $f$ Med registry based study

4 Robert E, Francannet C, Robert JM. Le registre de malformations de la région Rhone-Alpes/Auvergne. Intéret et limites de la tératovigilance. Onze années d'expérience (1976-1986). ₹ Gynecol Obstet Biol Reprod 1988;17:601-7. 5 Källén B. Search for teratogenic risks with the aid of malformation registries. Teratology 1987;35:47-52.

6 Croen LA, Shaw GM, Jensvold NG, Harris J. Birth defects monitoring in California: a resource for epidemiologic monitoring in California: a resource for epidem

7 Källén B, Winberg J. Multiple malformations studied with a national register of malformations. Pediatrics $1969 ; 44: 410$ 17

8 Källén B. Epidemiology of human reproduction. Boca Raton, Florida: CRC Press, 1988:31-5.

9 Mantel N, Haenszel W. Statistical aspects of the analysis of data from retrospective studies of disease. $\mathcal{f}$ Natl Cancer Inst 1959;22:719-48.

10 Miettinen OS. Simple interval estimation of risk ratio. $\mathrm{Am} \mathcal{F}$ Epidemiol 1974;100:515-6.

11 Breslow NE, Day NE. The analysis of case-control studies. Lyon, France: IARC Scientific Publications No 32, 1980.

12 Armitage P. Test for linear trend in proportions and frequencies. Biometrics 1955;11:375-86.

13 ICBDMS. Congenital malformations worldwide. A report from the International Clearinghouse for Birth Defects Monitoring Systems. Amsterdam: Elsevier, 1991.

14 Castilla EE, Orioli IM. Prevalence rates of microtia in South America. Int $\mathcal{F}$ Epidemiol 1986;15:364-8. 